\title{
PENSAMENTO MISSIONÁRIO ESTADUNIDENSE E EVANGELIZAÇÃO PARA O BRASIL EM FINS DO SÉCULO XIX: ALGUMAS CONSIDERAÇÕES
}

\author{
US MISSIONARY EVANGELISM AND THOUGHT FOR THE \\ PURPOSES OF BRAZIL IN THE NINETEENTH CENTURY: SOME \\ CONSIDERATIONS
}

\author{
Guilherme Ferreira Oliveira \\ Mestre - Universidade federal de São João Del-Rei \\ E-mail: mrguiferreira@yahoo.com.br
}

\begin{abstract}
RESUMO:Neste artigo investigamos as principais ideias do missionarismo protestante estadunidense, compreendendo de que maneira alguns autores como Johnatan Edwards e Josiah Strong influenciaram o pensamento das missões modernas, reforçando as idéias de excepcionalidade e providencialismo presentes no imaginário estadunidense. Por outro lado procuramos ressaltar que a construção do pensamento missionário está em mesma medida relacionado com as noções de progresso e civilização, na qual modernizar o mundo também passava por aspectos religiosos e morais. Com isto queremos salientar de que maneira esses pressupostos ideológicos podem lançar luz à atuação do missionarismo protestante no Brasil.
\end{abstract}

PALAVRAS-CHAVE: Missionarismo protestante. Pensamento missionário. Protestantismo estadunidense.

ABSTRACT: In this paper we investigate the major ideas of the American Protestant missionarism, including how some authors as Jonathan Edwards and Josiah Strong influenced the thinking of modern missions, reinforcing the ideas of exceptionalism and providentialism present in the American imagination. On the other hand tried to emphasize that the construction of the missionary thought in equal measure is related to the main concepts of the Enlightenment project of progress and civilization, in which the modernizing world also passed moral and religious aspects.

KEY WORDS: Protestant missionarism. Missionary thought. American Protestantism. American exceptionalism. Modernity and religion.

\section{Introdução}

Os estudos acerca das relações traçadas entre o protestantismo ${ }^{1}$ e a sociedade brasileira têm recebido, a partir das duas últimas décadas, certa atenção da ciência histórica,

\footnotetext{
${ }^{1}$ Entendemos como protestantismo a corrente religiosa que se configurou no século XVI, representada pela ruptura com a Igreja Católica. O protestantismo surgiu com a Reforma no século XVI, e desde aquele momento, suas posturas teológicas de sacerdócio universal e de leitura da Bíblia, contribuíram para o surgimento de diversas denominações em diferentes contextos e temporalidades, constituindo uma "pluralidade de protestantismos" determinados historicamente. Assim, é inútil procurar uma unicidade protestante, sobretudo
}

Oficina do Historiador, Porto Alegre, EDIPUCRS, v. 7, n. 2, jul./dez. 2014, p. 97-117. 
influenciados pelos trabalhos de outras áreas das Ciências Sociais que há mais tempo investigam o tema no país ${ }^{2}$. A crescente atuação de indivíduos ou setores que são englobados na categoria de "protestantes" nos espaços e nas atividades públicas acompanhado da adesão cada vez maior às denominações protestantes e, sobretudo, às igrejas pentecostais, sugere aos historiadores que é necessário investigar os processos culturais e sociais envolvidos na relação entre o Brasil e o protestantismo em determinadas temporalidades. Recentemente, algumas pesquisas começaram a se dedicar ao tema, e embora de maneira tímida, começam a iluminar algumas questões sobre esta relação, mas ainda de forma isolada e fragmentada ${ }^{3}$. Esses estudos se concentram nas atividades legitimadoras dos protestantes no país, como a fundação de escolas e a produção literária, e ainda que estejam contribuindo substancialmente para compreensão do tema, muitas vezes deixam de ressaltar os pressupostos ideológicos envolvidos na atividade missionária do protestantismo estadunidense, uma vez que foram estes os principais protestantes interessados na evangelização do país ${ }^{4}$.

após as guerras religiosas na Inglaterra no século XVII e principalmente depois das ondas de efervescência religiosa nos Estados Unidos, nos dois séculos que se seguiram - sobre os movimentos de efervescência ver, por exemplo, MENDONÇA, A. G. O Celeste Porvir. A inserção do protestantismo no Brasil. São Paulo: Editora da Universidade de São Paulo, 2008, p. 82 - 84. Ainda assim, convencionou-se utilizar o termo protestantismo, sobretudo para designar todas as filiações que se seguiram após a Reforma do século XVI e que se vincularam de alguma maneira a suas matrizes teológicas, se opondo drasticamente ao catolicismo.

${ }^{2}$ Para um histórico da historiografia protestante no Brasil, ver WATANABE, T. H. B. De Pastores a Feiticeiros: a historiografia do protestantismo brasileiro (1950-1990), Dissertação de Mestrado, UNESP, 2006. Ver ainda do mesmo historiador a tese de doutorado, Escritos nas Fronteiras: os livros de História do Protestantismo Brasileiro (1928-1982).UNESP, 2011. O primeiro historiador acadêmico a se dedicar ao tema foi EmileGuillaume Leonard, que escreveu $O$ iluminismo num protestantismo de constituição recente (1949) e $O$ Protestantismo Brasileiro (1950). No entanto, da década de meados da década de 1950 até início da década de 1990, os trabalhos publicados sobre o protestantismo no Brasil foram predominantemente estudos sociológicos e antropológicos, como por exemplo, o livro Protestantismo e Repressão (1971), de Rubem Alves e Celeste Porvir-A Inserção do Protestantismo no Brasil (1984), do sociólogo Antonio Gouveia Mendonça, este último provavelmente o maior estudo sistemático sobre o tema no país e texto fundamental para os historiadores. Sobre esse tema ver ainda CÉSAR, W. Para uma Sociologia do Protestantismo Brasileiro. Petropólis, Vozes, 1973 e RIBEIRO, Lidice M. P. O protestantismo brasileiro -objeto em estudo. REVISTA USP, São Paulo, n.73, p.117129, março/maio 2007.

${ }^{3} \mathrm{~A}$ historiografia sobre o protestante começou a crescer na década de 2000, com muitos trabalhados amparados pela História Cultural Francesa, mas ainda de forma descontínua e fragmentada. Um dos principais trabalhos é SANTOS, Lyndon de Araújo. Protestantismo e modernidade: os usos e sentidos da experiência histórica no Brasil e na América Latina. Projeto História, São Paulo, n.37, dez. 2008. Há ainda uma produção de trabalhos acerca da relação entre protestantismo e educação, como o texto p. 29-42, MATOS, Alderi Souza. O Colégio Protestante de São Paulo: um estudo de caso sobre o lugar da educação na estratégia missionária da igreja. In: Fides Reformata, 4/2, 1999. Contudo, apesar de suas valiosas contribuições, estes estudos se concentram na atuação do protestantismo missionário no Brasil e se distanciam do estudo do protestantismo estadunidense, o que, como pretendemos demonstrar neste artigo, poderia ampliar o escopo analítico sobre o tema. Um texto que trata sobre o protestantismo estadunidense, ainda que de diferente ponto de vista e objeto do trabalhado aqui, é ROCHA, Daniel. Os fundamentos de um reino milenar: expectativas milenaristas e engajamento político na história do fundamentalismo religioso estadunidense. In: Fronteiras, Dourados, MS, v. 12, n 12, p. 203225 , jan./ jun. 2010.

${ }^{4} \mathrm{~A}$ grande expansão do protestantismo no Brasil se deu a partir da segunda metade do século XIX, propagada, sobretudo, pelos missionários dos Estados Unidos, como destaca Mendonça, ver MENDONÇA, A. G. op. cit., p. 44. A presença protestante no período colonial foi esparsa e não especialmente interessada na expansão da sua fé, como foram os casos da França Antártica (1555) e o domínio holandês em Pernambuco; sobre este aspecto ver BICALHO, M. F. B. A França Antártica, o corso, a conquista e a "peçonha luterana". História, São Paulo, v. 27, p. 29, 2008 e VAINFAS, R. O Plano para o Bom Governo dos Índios: um jesuíta a serviço da evangelização calvinista no Brasil holandês.CLIO. Série Arqueológica (UFPE), v. 27, p. 145-162, 2009.

Oficina do Historiador, Porto Alegre, EDIPUCRS, v. 7, n. 2, jul./dez. 2014, p. 97-117. 
Ao longo das últimas décadas do século XIX e início do século XX, o Brasil recebeu membros de diversas denominações protestantes interessadas em divulgar o evangelho e suas formas de compreensão do mundo, inaugurando a grande atividade das missões protestantes no Brasil. Os estadunidenses, cada vez mais interessadas na América Latina, como um campo de atuação político, religioso e cultural, foram os grandes evangelizadores do período, seguidos dos ingleses e escoceses ${ }^{5}$. No país, esses missionários criaram escolas - Podemos citar, por exemplo, a Escola Americana, fundada pelo presbiteriano Ashbel Simonton em 1870, no mesmo ano funda-se a Escola América fundada em São Paulo, por George Chamberlain; Martha Watts criou em 1881 a primeira escola metodista, o Colégio Piracicabano; o Colégio Americano de Petrópolis (1895) e o Colégio Izabela Hendrix (1904) em Belo Horizonte - e tiveram uma intensa atividade de publicação de jornais e de textos exegéticos (MATOS, 2009, p. 29) ou por vezes se ligaram a pessoas do governo, como é o caso do metodista James Cooley Fletcher (1823 - 1901), que se aproximou de figuras proeminentes do Império, como Aureliano Tavares Bastos ${ }^{6}$.

No entanto, ainda que historiadores se dediquem às diversas atividades dos missionários no país, as práticas e representações de Brasil elaboradas por essas pessoas só adquirem inteligibilidade quando conhecemos o contexto e a intenção em que esses produtos culturais foram produzidos. Em outras palavras, para compreender os missionários estadunidenses é preciso examinar também quais foram os pressupostos intelectuais e ideológicos que deram sentido as suas atividades e qual seu contexto e intenção de produção ${ }^{7}$. É certo que este é um debate complexo e com muitas particularidades e a proposta deste artigo não é esclarecer todos os aspectos do pensamento missionário protestante nos Estados

\footnotetext{
${ }^{5}$ Sobre este aspecto ver CAVALCANTI, H. B. O projeto missionário protestante no Brasil do século 19: comparando a experiência presbiteriana e batista. In: Revista de Estudos da Religião, n 4, p. 61 - 93, 2001.

${ }^{6}$ Sobre a relação de Fletcher com homens brasileiros ver VIEIRA, David Gueiros. O protestantismo, a maçonaria e questão religiosa no Brasil. Distrito Federal: Editora UNB, 1980. Fletcher, ao lado do distribuidor de bíblias, Daniel P. Kidder, escreveu um importante livro sobre os brasileiros e uma análise desta obra pode ser encontrada em OLIVEIRA, D. V. A "sólida e estável” Monarquia nos Trópicos: Imagens sobre o Brasil e os Brasileiros no livro Brazil and Brazilians -portrayed in Historical and descriptive sketches, 1857.Dissertação apresentada à Faculdade de Filosofia, Letras e Ciências Humanas da Universidade de São Paulo, 2013.

${ }^{7}$ É preciso salientar que não há a intenção de apontar os limites do religioso e suas fronteiras com o mundo social, por não pensar que seus aspectos se fecham nos âmbitos estritamente teológicos e espirituais. É preciso antes de tudo pensar a religiosidade como elemento constituinte na sociedade e nos indivíduos, e lembrar que de certa forma todos os homens lidam com a religião, seja submetendo-se a ela, contradizendo suas palavras, recusando seus ensinamentos ou a usando para construir formas próprias de conceber o sagrado. A religião só pode assim ser compreendida tendo em vista que suas formas são geradas em contextos históricos e frutos de processos sociais mais complexos e amplos.
}

Oficina do Historiador, Porto Alegre, EDIPUCRS, v. 7, n. 2, jul./dez. 2014, p. 97-117. 
Unidos. Nossa proposta é apontar algumas chaves de leitura apresentadas pela historiografia das missões estadunidense, as quais ainda não são do conhecimento de todos os interessados em investigar esta temática no Brasil, e assim sugestionar que os historiadores possam pensar nessas perspectivas em seus trabalhos ${ }^{8}$.

Há uma ampla literatura sobre o tema nos Estados Unidos, os chamados missions studies, que em 2004 produziu uma coleção de livros sobre o assunto publicados sobre o título geral de Studies in the History of Christian Missions, com artigos sobre a historiografia das missões e com pesquisas recentes sobre história intelectual, cultural e social neste campo ${ }^{9}$, além da obra The Blackwell Companion to Protestantism (2006), que inclui artigos sobre diversas temáticas de grandes pesquisadores sobre o protestantismo em língua inglesa. A intenção Deste artigo é destacar quais as principais matrizes intelectuais apontadas por esta historiografia, com o intuito de refletir sobre o projeto das missões protestantes para o Brasil.

Para tanto, neste trabalho temos como orientação os esquemas interpretativos da historiografia religiosa italiana $^{10}$, com a história das representações e a com a história intelectual francesa ${ }^{11}$. Sobre a primeira abordagem, seguimos os métodos, as perspectivas e os

\footnotetext{
${ }^{8}$ Neste caso é valioso citar a pesquisa de mestrado que procurou traçar esse diálogo entre o pensamento missionário estadunidense, através da obra The Evangelical Invasion (1910), do missionário presbiteriano Samuel R. Gammon, destacando as matrizes ideológicas e os diálogos intelectuais inscritos nas imagens de Brasil elaboradas pelo missionário. Ver OLIVEIRA, Guilherme F. "Para a glória de Deus e para o progresso dos homens": pensamento missionário norte-americano e representações de Brasil a partir The Evangelical Invasion (1910), de Samuel R. Gammon. Dissertação apresentada ao Programa de Pós-Graduação em História da Universidade Federal de São João del-Rei, 2014.

${ }^{9} \mathrm{~A}$ coleção conta com a contribuição dos principais especialistas na história das missões protestantes em língua inglesa, como Andrew Porter, Wilbert Shenk e Brian Stanley. Os onze volumes se dedicam ao estudo das missões no seu período de maior atuação, ou seja, fins do século XVIII até meados do século XX. Seus temas variam entre aspectos teológicos, políticos e históricos e estudos de caso das missões em países do Oriente. Para este artigo fazemos largo uso de SHENK, Wilbert R (editor). North American Foreign Missions, 18101914: Theology, Theory, and Policy. Michigan / Cambridge, U.K.: Wm. B. Eerdmans Publishing Co, 2004.

${ }^{10} \mathrm{~A}$ escola italiana das religiões também pode contribuir substantivamente para o desenvolvimento desta pesquisa, sobretudo por ressaltar os aspectos antropológicos e a historicidade da religião. Para autores como o precursor Raffael Pettazoni e Nicola Gasbarrro, o mais influente destes nos estudos de história e antropologia no Brasil, é fundamental que pensemos a religião e os seus sentidos como produtos culturais ocidentais, localizados temporal e espacialmente. Nessa perspectiva, esses autores apontam as pretensões universalizantes da religião e as formas pelas quais ela procura se justificar enquanto tal. Gasbarro sugere ainda que dentre essas formas, "a religião e a civilização constituem as maiores generalizações antropológicas da modernidade" e por este autor trabalhar com categorias analíticas próximas das nossas, acreditamos que o contato com essa historiografia será bastante profícuo em nossa investigação. Ver SILVA, Eliane Moura. Entre religião, cultura e história: a escola italiana das religiões. In: Revisa de Ciências Humanas, Viçosa, v. 11, n. 2, p. 232, jul.dez. 2011.

${ }^{11}$ Com o objetivo de ampliar os limites analíticos, compreendemos os missionários como intelectuais, uma vez que são produtores e mediadores culturais. Seguimos aqui a nova abordagem da História Intelectual, na qual o
}

Oficina do Historiador, Porto Alegre, EDIPUCRS, v. 7, n. 2, jul./dez. 2014, p. 97-117. 
problemas propostos pela História Cultural ao estudo da religião, que a procura entender dentro de uma consciência histórica e social, e mesmo que seus temas sejam supranaturais, a religião é conduzida por homens e para homens. Essa abordagem não abandona a relação entre História e Teologia, mas não dá a ela status espiritual, e antes a compreende como uma ciência humana, e apesar de seu caráter profundamente metafísico e especulativo, muito pode ajudar a entender o estabelecimento das religiosidades (MATA, 2010, p. 20).

Como há uma proposta universalizadora nas religiões e nossos sujeitos históricos atuam mesmo como agentes que procuram legitimar essa percepção, através da linguagem e das práticas, elas se constituem como representações coletivas, procurando se impor por estratégias $^{12}$ forjada pelos próprios grupos. Destarte, neste trabalho nos valemos das discussões desenvolvidas por Roger Chartier, que compreende essas representações como as categorias que organizam e constroem a percepção do real, terminando por orientar os atos e as práticas mais cotidianas (CHARTIER, 2012). A representação surge assim como uma, das muitas vozes, presentes na realidade social, esta que é interpretada pelos grupos e indivíduos levando em conta esquemas próprios de classificação.

Neste artigo, especificamente, procuramos percorrer os dois principais nomes que influenciaram o pensamento missionário estadunidense ao longo de todo século XIX e de que maneira estes autores reforçaram as ideias de excepcionalidade e providencialismo presentes na auto-representação de autores e personalidades estadunidenses ${ }^{13}$, as quais estiveram presentes nas visões de mundo de alguns missionários que chegaram ao Brasil e constituíram parte de suas representações de Brasil à luz destas perspectivas. Por outro lado, apontamos ainda como a solução regeneradora que esses missionários sugeriam para o Brasil era a modernização civilizadora, sobretudo pela via da educação, compreendida como estratégia missionária de inserção e atuação no meio social brasileiro.

termo intelectual é amplo e apresenta um caráter essencialmente polissêmico. Sirinelli aponta duas acepções para o termo que engloba tanto os criadores como os mediadores culturais, e, portanto mais ampla do que a utilizada até meados década de 1970. Ver SIRINELLI, Jean-François. Os Intelectuais. In: RÈMOND, R. REMOND, René (orgs). Por uma história política. Rio de Janeiro: Editora FGV, 2003 e DOSSE, F. História e Ciências Sociais. Bauru, SP: Edusc, 2004.

${ }^{12}$ No entanto, não conferimos a essa estratégia um valor total, uma vez que consideramos os homens históricos como passíveis de arranjar o que não estava planejado, de constituir inovações e inventar novas situações frente a problemas inesperados.

${ }^{13}$ Sobre este ponto, a pesquisa de Cecília Silva Azevedo é bastante esclarecedora. Ver, sobretudo, AZEVEDO, Cecília Silva. A santificação pelas obras: a experiência do protestantismo nos EUA. Tempo. Revista do Departamento de História da UFF, v. 6, n.11, p. 111-129, 2001 e O sentido da Missão no Imaginário Político Norte-Americano. Revista de História Regional -UEPG, Brasil, v. 3, n.2, p. 77-90, 1998. 


\section{O missionarismo protestante estadunidense}

Se ao longo dos séculos XVI e XVII o missionarismo católico fez avanços substanciais no Novo Mundo, especialmente na América Latina, os missionários protestantes só avançaram no mesmo terreno nos século XIX e XX. Os historiadores do protestantismo estadunidense, como Werner Ustorf, Brian Stanley e Wilbert R. Shenk, afirmam que foi ao longo do século XIX que empresa missionária protestante se fortaleceu a partir da criação de sociedades missionárias autônomas e da produção de obras feitas para justificarem a atividade das missões, estas que circulavam entre os seminários e as instituições. A primeira sociedade para missões estrangeiras foi criada em 1810, a American Board of Commissioners for Foreign Missions (ABCFM), que enviou diversos missionários para algumas regiões da América Latina, mas, sobretudo para países da Ásia e da África, considerados os mais necessitados da palavra protestante ${ }^{14}$. Archibald G. Baker, um pensador protestante da Universidade de Chicago, escreveu em 1926 que "o pensamento missionário ainda está num processo de formação - um estágio de transição do século XIX ao XX” (BAKER, p. 399, 1926) e de fato, foi neste período, que os países da Ásia, da África e da América Latina receberam um grande número de missionários protestantes estadunidenses.

No Brasil, a presença protestante anterior a esse período não se dedicou ao missionarismo e apesar de que possivelmente houvesse formas de proselitismo, a intenção dos imigrantes não era, em primeira estância, a divulgação religiosa. Durante a primeira década do século XIX, a partir dos Tratados de 1810, que permitiram a liberdade de culto dos ingleses no Brasil, e com a Constituição de 1824, que ampliou essa liberdade religiosa às pessoas de outros países ${ }^{15}$, - apesar de manter o monopólio católico - alguns distribuidores de bíblias e missionários começaram a se investigar as possibilidades de missão no país. A partir

\footnotetext{
${ }^{14}$ David W. Kling, ao estudar o contexto de surgimento da ABCFM afirma que o grande contingente de missionários foi enviado para Índia e a China, principalmente. Ver KLING, D. W. The New Divinity and the Origins of the American Board of Commissioners for Foreign Missions. In: SHENK, Wilbert R (editor). North American Foreign Missions, 1810 - 1914: Theology, Theory, and Policy., p. 12.

${ }^{15}$ A Constituição de 1824 reafirmou o catolicismo como a religião do Império, no entanto proibiu a perseguição de acatólicos e permitiu a construção de locais de cultos, desde que não apresentassem forma exterior de tempo. Sobre o debate da liberdade de culto no Império e sua relação com o protestantismo, ver PEREIRA, Rodrigo da Nóbrega Moura. A salvação do Brasil: as missões protestantes e o debate político-religioso do século XIX. Tese (doutorado). Universidade do Estado do Rio deJaneiro: IFCH, p. 73 - 76, 2008.
} 
da década de 1830 algumas sociedades missionárias norte-americanas começam a interessarse pelo Brasil e em 1835, a partir de uma investigação feita pelo Reverendo Foutain E. Pitts que esteve no país ao lado de Justin Spaulding, embarcou para o Rio de Janeiro, o metodista estadunidense Daniel P. Kidder ${ }^{16}$, encarregado de distribuição de Bíblias. É durante este século que chegaram no Brasil os primeiros evangelizadores, como o metodista Robert R. Kalley que, acompanhado de sua esposa Sarah Poulton Kalley, aportaram no país em 1855, e o presbiteriano Ashbel G. Simonton, que chegou ao Rio de Janeiro em 1859, marcando o período conhecido como "protestantismo de missão" no Brasil.

Esse movimento missionário do século XIX está profundamente associado às noções de providencialismo e excepcionalismo estadunidense, bastante presentes nesse período expansionista estadunidense. Por excepcionalismo (KOH, p. 1470 - 1528, 2003) entendemos a auto-representação de sua comunidade e de seu povo como únicos e extraordinários, podendo se manifestar em práticas e representações tanto seculares, como religiosas. No caso estadunidense, suas origens remontam à saída dos puritanos da Inglaterra e a constituição de uma nova sociedade nos Estados Unidos, momento chave que é com freqüência citado em situações-limites (BERCOVITCH, 1988), como enfrentamentos bélicos ou puramente simbólicos (FONSECA, 2007; AZEVEDO, 2011). Os teóricos do excepcionalismo acreditavam numa formação mitológica da sociedade norte-americana, na qual os peregrinos ou pais fundadores atravessaram o mar para fundar na América uma sociedade de eleitos, ou seja, repetindo a história bíblica do Êxodo e da formação de uma comunidade de escolhidos ${ }^{17}$. Essa auto-percepção como pertencente a um grupo excepcional, privilegiado e escolhido está

\footnotetext{
${ }^{16}$ Kidder escreveu ainda vários livros, dentre os quais três foram dedicados ao Brasil; o primeiro destes é uma tradução de um texto de Diogo Feijó sobre o celibato clerical, seguido da obra Sketches of Residence and Travel in Brazil (1845), este em dois volumes, um sobre reminiscências no Norte e outro no Sul do país, e Brazil and the Brazilians Portrayed in Historical and Descriptive Sketches (1868), este último escrito ao lado o missionário presbiteriano James Cooley Fletcher. Kidder esteve no Brasil de 1837 a 1840.

${ }^{17} \mathrm{Um}$ dos primeiros exemplos dessa percepção de excepcionalismo pode ser encontrado no séc. XVII. O sermão de John Winthrop, por treze vezes reeleito como governador de Massachussetts desde sua fundação em 1629, é um das mais incisivas amostras das intenções dos puritanos na nova terra, e não por caso aparece nos discursos públicos de políticos (As relações entre a alegoria do "city upon the hill" e a política americana contemporânea podem ser encontradas no artigo de FONSECA, Carlos da. Deus está do nosso lado: Excepcionalismo e Religião nos EUA. In: Revista Contexto Internacional. Rio de Janeiro, vol. 29, $\mathrm{n}^{\circ} 1$, janeiro/junho 2007,. Ver ainda AZEVEDO, Cecília Silva. A santificação pelas obras: a experiência do protestantismo nos EUA.Tempo. Revista do Departamento de História da UFF, v. 6, n.11, p. 111129, 2001) A narrativa da história de Winthrop foi repetida ao longo da história norte-americana e faz referência a uma parábola bíblica do livro de Mateus que versa sobre a emergência de uma "cidade sobre a colina". Nos termos de Winthrop, destarte, tornou-se o chamado para uma missão histórica convocada por Deus, que estaria sendo conduzida pelos pais peregrinos na América. A cidade era Boston, a capital da Nova Inglaterra, onde se criaria uma cidade de homens santificados e que unidos caminhariam para a salvação, conforme predizia a história cristã.
}

Oficina do Historiador, Porto Alegre, EDIPUCRS, v. 7, n. 2, jul./dez. 2014, p. 97-117. 
relacionado à incumbência de salvação espiritual e moral dos que não fazem parte deste grupo de escolhidos, em outras palavras, o resto do mundo - é o que chamamos de providencialismo.

Segundo o historiador das missões protestantes David W. Kling, essa noção de providencialismo permeou a criação das primeiras sociedades missionárias, se tornando a principal ideia das missões norte-americanas, na qual os missionários estadunidenses são responsáveis pela "verdadeira cristianização" de toda a humanidade (KLING, p. 11 - 38, 2004). Duas obras são fundamentais tanto para a constituição desse pensamento nos primeiros momentos no interior das sociedades missionárias, bem como de sua manutenção, afinal, foram consideradas obras essenciais nos círculos missionários até meados do século XX (KLING, p. 11 - 38, 2004). Ambos os textos, Life of Brainerd (1749) e Freedom of Will (1754), foram escritos pelo teólogo Johnatan Edwards (1703 - 1758), o qual experenciou e defendeu os movimentos de avivamento, o que deixou em sua obra um caráter de ênfase no contato espiritual acompanhado de um desejo de transformação da vida da comunidade. $\mathrm{O}$ primeiro texto é considerado como o principal divulgador do princípio da "benevolência desinteressada" e o segundo livro ressalta a capacidade humana em alcançar a graça divina e o seu dever cristão em espalhar o Evangelho. Apesar de Edwards ressaltar a soberania de Deus, nesses dois trabalhos o autor desenvolver a noção da "benevolência desinteressada"18 como parte da obrigação do cristão e também do protestante estadunidense.

Apesar de estes textos terem sido escritos em meados do século XVIII, foi só no início do XIX, com o surgimento das sociedades missionárias que os livros de Edwards se tornaram referência (KLING, p. 29, 2004). Com a divisão das igrejas entre norte e sul durante a Guerra Civil (1861-1865) o missionarismo cresceu substancialmente e, sobretudo aumentaram as sociedades interessadas no missionarismo estrangeiro, contudo mantendo o Oriente como o principal destino missionário ${ }^{19}$. No período após a Guerra Civil, o pensamento missionário manteve as mesmas premissas de excepcionalismo e providencialismo, o que pode ser

\footnotetext{
${ }^{18}$ Este conceito ficou amplamente conhecido com o livro de Jonathan Edwards, Life of Brainerd (1749), da Igreja Congregacional da Nova Inglaterra. Em suma, podemos caracterizar este princípio como o sacrifício individual em nome dos interesses alheios. Nos Estados Unidos a noção bíblica do altruísmo foi associada à necessidade de reparar a dívida com as nações menores, o que chamavam de "benevolência desinteressada". O "altruísmo nacional" não pode ser separado do impulso religioso, uma vez que compunham faces de uma mesma moeda. Ver KLING, David W. op cit., p. 12.

${ }^{19}$ Num artigo publicado em 1926, o pesquisador protestante Archibald G. Baker, da Universidade de Chicago fazendo um balanço dos últimos vinte cinco anos (1901 - 1926) sobre o pensamento das missões protestantes, deixa claro a tendência oriental das missões até este período. Ver BAKER, A. G. op. cit.
} 
verificado com a publicação da terceira obra, em ordem cronológica, de grande importância para a formação do pensamento missionário: Our Country (1885), de Josiah Strong (18471916).

Strong foi um dos principais clérigos protestantes, e grande incentivador do missionarismo interno e externo. Alguns historiadores reconhecem em seu trabalho uma face do imperialismo evangélico ${ }^{20}$, especialemente por sua principal obra ser considerada a versão religiosa do Destino Manifesto, justificando esta ideologia por vias teológicas para os leitores dos círculos protestantes. Os principais temas do livro são a responsabilidade cristã e o destino salvacionista dos Estados Unidos se tornando um dos textos mais importantes e populares entre seus contemporâneos (EDWARDS, P. 164, 2004) .

Segundo o historiador Edward W. J. Deichmann, as principais influências de Our Country são a Teologia do Pacto, que no livro de Strong se aproxima da noção de que a salvação depende não só da graça, mas também da capacidade evangelizadora do fiel (EDWARDS, p. 165, 2004); e pela tendência em considerar que a construção do reino de Deus depende da reorganização da sociedade humana através da "verdadeira religião" (EDWARDS, p. 167, 2004). É certo que estas considerçaões não configuram uma alteração crucial no pensamento missionário, pois as considerações de Strong, são em parte, continuidade do pensamento de Edwards. Para a maioria dos autores, o grande avanço no livro está no capítulo 13, The Anglo-Saxon and the World's Future, onde Strong introduziu uma interpretação religiosa da superioridade anglo-saxônica a partir de teorias científicas do fim do século XIX (EDWARDS, p. 182, 2004).

A principal referência para este capítulo é a conhecida obra de Charles Darwin, $A$ Origem das Espécies (1859) ${ }^{21}$. Segundo Deichmann Edwards, por volta de 1875 grande parte dos pensadores protestantes estavam convecidos da necessidade de acomodar aos ditames cristãos a teoria evolucionista, não a comprendendo como uma história natural, mas como um paradigma da grandeza e da complexidade da operação divina. Dessa maneira, o anglo-

\footnotetext{
${ }^{20} \mathrm{O}$ termo "imperialismo evangélico" aparece algumas vezes na historiografia das missões norte-americanas, e apesar de não termos encontrado uma definição precisa por parte dos próprios autores, entendemos que ele está relacionado à expansão protestante em fins do século XIX e início do século XX e sua relação com a divulgação de valores nacionalistas, capitalistas e muitas vezes de superioridade racial. Ver PORTER, Andrew. Missions and Empire, c. 1873 -1914. Cambrigde Histories Online: Cambridge University Press, 2008, o. 560 - 575; HOBSBAWN, Eric. A Era dos Impérios, 1875 -1914. São Paulo: Paz e Terra, 2011, p. 120 e p. 132.

${ }^{21} \mathrm{O}$ artigo de Edwards cita vários trabalhos interessados em investigar essa relação. Uma das análises mais importantes está em ROBERTS, Jon. Darwinism and the Divine in America: Protestant Intellectuals and Organic Evolution, 1859 - 1900. Madison: University of Wisconsin Press, 1988.
} 
saxonismo de Strong era " uma interpretação religiosa de uma teoria científica, informado pela sua firme concepção acerca do poder transformador do evangelho cristão e sua crença na sanção divina sobre o papel dos Estados Unidos na inauguração do reino de Deus na terra" (EDWARDS, p. 183, 2004). Essa virtude - designada por Deus - era predominantemente intelectual na ascepção de Strong e de outros pensadores protestantes, e essa espiritualização da noção de raça se manteve como uma das bases do protestantismo estadunidense no período.

Nesse sentido, Our Country é ainda muitas vezes relacionado a principal corrente do pensamento missionário protestante no início do século XIX, o Evangelho Social ${ }^{22}$ (Social Gospel). Essa é a principal vertente da teologia liberal surgida no alvorecer do século XX, de tendência pós-milenarista e defensora do melhoramento social como condição para o segundo retorno de Cristo, e mais uma vez, relacionada com a situação histórica expecional considerada por eles - dos Estados Unidos nos desígnios divinos. Há algumas controvérsias sobre a definição do Evangelho Social. Em 1972, o historiador Sydney E. Ahlstrom, a caracterizou como a mais influente vertente da teologia liberal, notadamente progressista e nacional e muitas vezes atraída pelos desejos de reforma social (ALSTROM, 1972) . Publicada três anos mais tarde, a análise de William Hutchison fez resslavas na interpretação de Ahlstrom, que foi visto fora dos contornos nacionais, ou seja, não era um peculiaridade estadunidense, e que suas influências ultrapassam os limites do país, apesar de apresnetar um desenvolvimento histórico e cultural particular nos Estados Unidos. Hutchison não encontra no Evangelho Social características reformadoras, sugerindo que muitos setores conservadores estiveram envolvidos com essas ideias (HUTICHISON, 1974). Para este historiador, o Evangelho Social é perpassado pela noção de que a salvação social precede a individual e assim pode ser incluído como uma vertente da teologia liberal.

O trabalho de Janet F. Fishburn (2001), contudo, discorda de Hutchison justamente neste último ponto; segundo a historiadora, alguns ícones do movimento defendiam como necessidade primeira a conversão individual, e portanto, este é um movimento de direcionamento antes de tudo teológico, e não pode ser incluído no grupo das teologias liberais sem que se levantem essas ressalvas. Janet sugere que o Evangelho Social tinha tonalidades essencialmente românticas e otimistas, em que o missionário era visto como herói

\footnotetext{
${ }^{22}$ Alguns autores investigam a relação entre o Evangelho Social e a divulgação de uma espécie de protestantismo liberal na América Latina. Podemos citar Jean Pierre-Bastian (1990) e Carlos Raúl Sosa Siliézar (2007).

Oficina do Historiador, Porto Alegre, EDIPUCRS, v. 7, n. 2, jul./dez. 2014, p. 97-117.
} 
progressita que, sob orientação direta de Deus e para Deus, atuava no melhoramento social, não essencialmente reformista. Derivado da empresa missionária, O Evangelho Social se tornou mais tarde sua principal noção norteadora (FISHBURN, 2004).

Em todo caso, o que nos interessa ressaltar é que as práticas e representações dos missionários protestantes dos Estados Unidos que vieram para o Brasil, foram em mesma medida, permeados dessas noções de excepcionalidade e providencialismo. Para ilustrar essa relação, um exemplo significativo é o trecho escrito em 1816 na revista da American Bilble Society $^{23}$ (ABS) sobre a distribuição de bíblbias e a responsabilidade estadunidense com a expansão do protestantismo:

Povo dos Estados Unidos

Já foste convidado a uma empresa de tanta grandeza e glória? Não valorizas ali Sagradas Escrituras? Não as valoriza como contendo tua mais doce esperança, tua mais eletrizante alegria? Podes admitir a ideia de que tu foste apático nos teus esforços de distribuí-las, enquanto o resto da cristandade está despertada e alerta? (...) Será possível não veres, nesse estado de coisas humanas, um poderoso movimento da Divina Providência?

Vinde, compatriotas, co-cristãos, unamo-os à sagrada aliança ${ }^{24}$.

Um poscionamento interessante sobre esse assunto é o de Hugh C. Tucker, que atuou como distribuidor de bílbias no Brasil no início do século XX também pela American Bible Society, e escreveu em livro The Bible in Brazil (1902) o seguinte trecho:

A investigação desse livro deveria sugerir, por fim, às mentes piedosas que pensaram na imensa na tremenda responsabilidade das pessoas cristãs dos Estados Unidos com a libertação dos brasileiros do jugo romano de escravidão e de tirania terrível a que eles foram escravizados ${ }^{25}$.

Em outros termos, as palavras de Tucker são permeadas das noções de excepcionalidade e, sobretudo, de obrigação salvacionista e providencial. O catolicismo, visto

\footnotetext{
${ }^{23}$ A Sociedade Bíblica Americana surgiu em 1816 a partir da fusão de numerosas sociedades bíblicas já existentes no país, com intuito de "estabelecer, sem demora, uma organização bíblica, para a circulação das Sagradas Escrituras sem notas ou comentários”. American Bible Society. Panoplist and Missionary Magazine, XII (1816), p. 269 apud REILY, Duncan Alexander. História Documental do Protestantismo no Brasil. $3^{\mathrm{a}}$ Ed. São Paulo: ASTE, 2003, p. 82.

${ }^{24}$ Idem, ibidem.

${ }^{25}$ TUCKER, H. C. The Bible in Brazil. Colporter Experiences. Young People's Missionary Movement of United States and Canada. New York: Flemming H. Revell Company, 1902, p. 6.
}

Oficina do Historiador, Porto Alegre, EDIPUCRS, v. 7, n. 2, jul./dez. 2014, p. 97-117. 
como mal de origem da sociedade brasileira, teria conduzido os homens do país a uma escravidão espiritual, e caberia aos protetantes estadunidenses revertem esse quadro. No mesmo sentido, uma citação de Samuel R. Gammon ${ }^{26}$, missionário presbiteriano no Brasil, é interessante para exemplificar esse ponto de vista. $\mathrm{O}$ autor afirma em seu texto:

O Brasil é nossa Samaria [atual território da Cisjordânia e Israel]. Quando o Salvador mostrou aos seus apóstolos o grande caráter missionário da igreja, indicou-lhes o conteúdo disto e o seu poder. (...) A Samaria se parecia com a fé dos judeus em sua forma mais corrupta, e da mesma maneira é a América Latina com o catolicismo. Por razões como estas sabemos que a América Latina é a Samaria para os protestantes norte-americanos"27.

Nesta citação encontramos as noções de excepcionalidade, uma vez que a conquista sagrada do Brasil é função dos Estados Unidos, bem como de providencialismo, uma vez que Deus teria orientado aos estadunidenses de que a salvação da América Latina era sua obrigação ética, moral e religiosa. Gammon nos permite pensar que a evangelização do Brasil também fo i vista a partir desta ótica messiânica e salvacionista, em que seu povo é designado e convidado por Deus para salvar a outra comunidade, levando seu modo de vida, enfim, sua civilização. O mais interessante é que, para Gammon, essa transposição civilizacional é também a repetição de uma história bíblica que os missionários eram chamados a cumprir no Brasil. No mesmo sentido, o missionário Thomas Wood, compartilhava de opinião de Gammon:

As igrejas norte-americanas começaram operações em pontos estratégicos, inclinadas a evangelizar o continente inteiro. As igrejas europeias, em sua maioria, estão deixando o continente só. Essas, a um grande custo, preocupam-se em cuidar de seus membros que emigraram para cá, fazem muito pouco pelas massas dominadas pelos padres. Para eles, é suficiente o que fazem em seu próprio hemisfério e estão deixando a América para os americanos. Tomara que as igrejas norte-americanas abram seus olhos e

\footnotetext{
${ }^{26}$ Samuel R. Gammon (1865 - 1928) nasceu na Virgínia, da terceira geração da família Gammon, que havia aportado nos Estados Unidos no sudoeste da Virgínia e no leste do Tenesse, oriundos da Escócia e da Irlanda. Estudou Filosofia e Teologia no Seminário de Bristol. Aportou no Brasil em 1889 e até 1893 dirigiu um colégio em Campinas. Neste mesmo ano transferiu-se para Lavras, fundando a primeira escola protestante da região. Para mais informações ver GAMMON, Clara. Assim brilha a luz: A vida de Samuel Gammon. Lavras: Imprensa Gammon, 1910, pp. 20-25.

${ }^{27}$ GAMMON, S. R. The Evangelical Invasion of Brazi or a half century of Evangelical Missions in the Land of Southern Cross. Richmond, Presbyterian ComMitee of Publications, p. 65
}

Oficina do Historiador, Porto Alegre, EDIPUCRS, v. 7, n. 2, jul./dez. 2014, p. 97-117. 
vejam a oportunidade que Deus tem reservado para elas em seu próprio hemisfério ${ }^{28}$.

Dessa forma, o pensamento de Thomas Wood é bastante próximo ao de Gammon - e nota-se também uma proximidade com a Doutrina Monroe ${ }^{29}$. No pensamento desses dois missionários, a evangelização da América Latina era uma obrigação dos Estados Unidos e naquele fim de século, com a diminuição do poder da Europa na região, advindo sobretudo com o rompimento das antigas colônias com a Espanha e Portugual, os protestantes poderiam executar suas atividades sem perseguição religiosa. Esse era considerado, portanto, o momento oportuno para que as sociedades missionárias avançassem no continente e epxandissem sua fé. Outro nome que compartilhava das mesmas perspectivas era Hubert Brown. Missionário presbiteriano no México entre os anos de 1880 - 1906 e autor do livro Latin America: the pagans, the papists, the patriots, the protestants, and the present problem $^{30}$ (1901), Brown afirmava, reafimando os mesmo posicionamentos descritos anteriormente:

Olhe então, por um momento, o tamanho de nosso Hemisfério Ocidental, no qual os Estados Unidos desempenham o papel mais proeminente. Nossa posição implica obrigações religiosas bem como políticas para o resto dos colegas americanos ${ }^{31}$.

\section{A modernidade seletiva e a expansão da civilização cristã}

Filhas de seu tempo, as missões modernas estiveram muito próximas da principal corrente de pensamento européia, o Iluminismo ${ }^{32}$. Assim, não nos é estranho que privilegiassem o regime político republicano, a expansão ecônomica capitalista e o incentivo

\footnotetext{
${ }^{28} \mathrm{O}$ trecho de Thomas Wood aparece no livro de P. H. Beach. Ver BEACH, Harlam P. Protestant Missions in South America. New York, p. 210, 1900.

${ }^{29}$ Sobre esse aspecto ver PIEDRA, Arturo. Evangelização protestante na América Latina: análise das razões que justificaram e promoveram a expansão protestante (1830-1960). São Leopoldo: Sinodal; Equador: CLAI, 2006, p. 30 -33.

${ }^{30}$ BROWN, Hubert W. Latin America: the pagans, the papists, the patriots, the protestants, and the present problem. New York: Young People's Missionary Movement of the United States and Canada, 1909.

${ }^{31}$ BROWN, H. op. cit., p. 15 .

${ }^{32}$ Sobre essa relação ver, sobretudo, o texto de STANLEY, Brian. Missions, Empire and the Hierarchy of Civilization. In: The World Missionary Conference, Edinburgh 1910. Cambridge: Eerdmans, 2009.
}

Oficina do Historiador, Porto Alegre, EDIPUCRS, v. 7, n. 2, jul./dez. 2014, p. 97-117. 
na educação como a garantia para um progresso contínuo. Um dos principais projetos do missionarismo protestante era a modernização do mundo, em outras palavras, interessava a divulgação das noções de uma civilização global que seguisse os modelos pré-ditados e experimentados pela Europa e, principalmente pelos Estados Unidos (USTORF, 2003, p. 397). Até este ponto, o projeto missionário protestante pode parecer muito próximo aos muitos projetos civilizadores dos Trópicos, encabeçada por naturalistas, políticos e pela "vanguarda capitalista" 33 desde meados do século XVIII - ou antes mesmo, desde o século XVI. A grande diferença destes projetos civilizadores seculares e do missionarismo protestante está, como era de se esperar, em privilegiar o caráter espiritual ao defender a expansão da alta civilização. Acreditavam na possibilidade e na necessidade do progresso contínuo, mas ele não se realizaria por si só, mas seria conduzido pela "verdadeira fé" e pelos modos de vida relacionados a ela. O progresso sem a fé, levaria a imobilidade e a sua própria destruição; mas a "fé verdadeira" levaria à inevitabildade do progresso. Assim, realizam-se dois projetos: o humano e iluminista, de melhoramento do homem e do mundo; e o divino, que é a salvação da humanidade, mas que é dependente da conclusão do projeto humano. Isso não leva a considerar que o projeto humano é prioritário, pois o progresso não é contínuo onde não há a "verdadeira fé". Não há assim uma oposição entre as relações sagradas e as profanas, e sim, uma coexistência negociada e desenvolvida no plano da cultura e da história.

Ao longo do século XIX houve uma grande tendência no pensamento missionário em incorporar as esperanças no progresso da humanidade como um desejo não só humano, mas sobretudo divino: a realização desse projeto levaria a uma única comunidade de homens, a dos cristãos, e a promessa do retorno de Jesus, assim, cumprir-se-ia. A teologia missionária foi dessa maneira conduzida a uma espiritualidade que não pretendia confrontar o método e a razão, o que os teólogos protestantes, baseando-se em Kant, chamaram de ideal da religião razoável (TILLICH, p. 74 - 75, 2010). Procurou-se diminuir os elementos considerados irracionais ou as formas de culto e rito que não tinham uma explicação quando confrontada com o pensamento racional. Reforçou-se com isso a afirmação sobre a força autônoma do

\footnotetext{
${ }^{33}$ Mary Louise Pratt classifica como "vanguarda capitalista" os viajantes europeus que desembarcaram nas Américas desde as primeiras décadas do século XVIII com o intuito de verificar as possibilidades de investimento e de exploração de recursos, além de alianças com a elite local. Um estudo sobre o discurso desta vanguarda capitalista (ancorada na incapacidade moral e histórica do povo das Américas Central e do Sul) está em PRATT, M. L. Os olhos do império: relatos de viagem e transculturação, p. 249-293.
} 
homem, seu poder de verificação e crítica da religião, bem como sua obrigação de eliminar o que ele considera supersticioso na crença.

O foco da religião, com isso, voltava a ser a hermenêutica da Bílbia, mas numa leitura que auxiliava a justificar os paradigmas modernos de igualdade, emancipação, liberação das mulheres ${ }^{34}$ - ressaltando o papel das missionárias no Brasil, como Carlota Kemper e Isabela Hendrix - e o direito do indivíduo, como ser consciente e munido de razão, escolher sua própria religião (USTORF, p. 397, 2012) e apesar da certeza de uma única fé verdadeira, os que não a adotassem não deveriam sofrer perseguições, pois fizeram sua escolha conscientemente. Para tanto era necessário conhecer a Bíblia, alfabetizar os homens para estarem aptos à leitura e à divulgação da perspectiva bíblica da História do mundo.

Desde a ruptura da Reforma, o protestantismo foi associado ao moderno e com frequência foi visto pelos analistas com uma pré-condição para o progresso. No século XIX essa posição se tornou mais firme com a consolidação das obras de E. Troeltsch, M. Weber e Paul Tillich e com a associação entre catolicismo, monarquia e atraso, de um lado, e protestantismo, república e avanço, de outro. O historiador não deve suspeitar que entre esses três fenômenos haja uma afinidade congênita; é preciso historicizá-los, pois as contradições e as possíveis aproximações estão inseridas em construções históricas e culturais específicas ${ }^{35}$. De fato, como destaca Vissert Hooft, as missões se tornaram prisioneiras da civilização moderna ocidental (VISSERT HOOFT, 1959).

O ideal civilizatório do protestantismo estadunidense ocupa grande parte das análises sobre este tema no Brasil ${ }^{36}$. Alguns desses estudos insistem apenas na relação entre o projeto

\footnotetext{
${ }^{34} \mathrm{Um}$ artigo interessante sobre o papel das mulheres protestantes no Brasil é SILVA, Eliane Moura. "Os Anjos do Progresso no Brasil”: as missionárias protestantes americanas (1870 - 1920). In: Rever, ano 12, $\mathrm{n}^{\circ} 1$, jan./jun. 2012.

${ }^{35}$ Sobre este tema ver WILLAIME Jean-Paul. $O$ protestantismo como objeto sociológico. In: Estudos da Religião: Revista Semestral de Estudos e Pesquisas em Religião. São Bernardo do Campo: Universidade Metodista de São Paulo, ano XIV, n ${ }^{\circ}$ 18, p. 13 - 37, jun. 2000. Texto disponível ainda na página eletrônica da Editora Metodista: http://editora.metodista.br/textos_disponiveis/er18cap1.pdf; FERREIRA, Valdinei Aparecido. Protestantismo e Modernidade no Brasil da utopia à nostalgia. São Paulo: Ed. Reflexão, 2010; OLIVEIRA, G. F. “Para a glória de Deus e para o progresso dos homens”..., op. cit., p. 89 - 92.

${ }^{36}$ Uma das principais referências à relação civilização-protestantismo pode ser encontrada no tópico Civilização Protestante e "Destino Manifesto", em MENDONÇA, A. G. O Celeste Porvir, p. 90-95. Cesar Amaral Romeiro Vieira também faz uma contribuição bastante interessante ao estudar o protestantismo estadunidense e o interesse de propagação da civilização moderna, no artigo Protestantismo estadunidense e o movimento civilizatório brasileiro. In: Publicação do X Simpósio Internacional Processo Civilizador. Em sua maioria, os textos produzidos pela área de Educação ressaltam a relação entre processo civilizador (Norbert Elias) e a estratégia protestante. Alguns desses estudos podem ser encontrados nas publicações dos pesquisadores do Departamento de Educação da Universidade Federal de Uberlândia.
} 
civilizador - entendido a partir das noções propostas por Norbert Elias ${ }^{37}$ - e a expansão do protestantismo no último quartel do século XIX, sem, contudo, procurar as relações entre o pensamento protestante do período e o contexto social estadunidense, uma vez que as crenças religiosas só são precebidas tendo em vista determinados contextos espaciais e temporais. Não há dúvidas de que os protestantes estiveram realmente interessados em divulgar meios mais racionais de organização social e industrial, bem como um novo sistema pedagógico, que incluía materiais, disciplinas e a própria forma de ensino (BARBANTI, P. 24, 1981).

No entanto, é preciso não perder de vista que na obra de Elias, a religião não foi vista como propulsora, por excelência, do processo civilizador, exceto quando essa é a ideologia do grupo ou da classe que a sustenta. Neste movimento civilizatório, se privilegia a prevalência do racional e do desenvolvimento sociocultural, e a história depende das ações e da cultura humana. Ao contrário, a perspectiva de história e progresso humano do protestantismo estadunidense, ainda que interessada na civilização moderna, é essencialmente teleológica e providencial. A dimensão civilizatória do pensamento protestante não pode ser unicamente explicada como parte do processo civilizador descrito por Elias, como se o próprio movimento missionário constituísse, em essência, uma vertente desse processo. A Assim, o processo civilizador não pode ser considerado o único motor do movimento de missões, mas uma, das muitas idéias que orientaram seus agentes e instituições. Contudo, é preciso extrapolar essa noção e como tencionamos mostrar nesse artigo, uma história intelectual, do imaginário ou das represnetações protestantes poderia ser bastante profícua para avançar na compreensão das relações travadas entre o portestantismo e a cultura brasileira.

\section{Considerações finais}

É fundamental compreender o pensamento protestante do século XIX para se investigar os projetos, os discursos, as práticas e as representações do protestantismo no Brasil. É possível acreditar que grande parte dos missionários que aportaram no país, tiveram

\footnotetext{
${ }^{37}$ Basicamente, a noção de civilização no sentido franco-britânico de Elias - civilização ou zivilization - se configura como uma tendência expansionista e contínua no campo da cultura, a partir da perspectiva ocidental. Na acepção de Elias, essa noção de civilização conduziu, desde fins da Idade Média, a mudanças de costumes e valores, que progressivamente e em longa duração, foram incorporados pelos indivíduos se tornando hábitos e noções predefinidas e transformadas historicamente. Ver ELIAS, Norbert. O processo civilizador, volume I: uma história dos costumes. Rio de Janeiro, Zahar, 2011, p.23.
}

Oficina do Historiador, Porto Alegre, EDIPUCRS, v. 7, n. 2, jul./dez. 2014, p. 97-117. 
contato com os livros de Edwards e Strong nos seminários e outros círculos missionários, e ainda que não partilhassem as mesmas perspectivas dessas obras, o pensamento das sociedades missionárias para as quais trabalhavam, era permeado pelas idéias de excepcionalidade estadunidense e de sua obrigação salvacionista.

Em mesma medida, o pensamento missionário foi bastante influenciado pelas noções de progresso humano e desenvolvimento civilizatório, acreditando numa convivência pacífica entre o avanço da modernidade e da religião. Dessa forma, a religião extrapolava os sentidos espirituais, sendo também uma influência moral na vida dos homens e uma condição para o avanço da sociedade.

O que procuramos mostrar é que o protestantismo que chegou ao Brasil em fins do século XIX e início do século XX carregava um pensamento que não é somente teológico, mas que está em constate contato com o pensamento científico e as condições culturais e sociais de seu tempo. Os missionários protestantes coletaram, analisaram e classificaram as culturas a partir de sua compreensão religiosa em todo o mundo, construindo um relato etnográfico muito próprio. $\mathrm{O}$ estudo dessas obras poderia revelar facetas ainda desconhecidas sobre as relações entre protestantes e católicos no início do século, e poderiam ainda apontar para processos de remodelação e reinvenção do projeto missionário diante de um universo religioso tão complexo que era - e continua sendo - o Brasil. Esta é uma seara ainda a ser desvendada pelos historiadores brasileiros, uma vez que existem uma série de livros escritos por missionários sobre o Brasil e que constituem um rico acervo ainda inexplorado ${ }^{38}$. Diante da observação de todos esses fatores, é certo afirmar que o protestantismo modificou-se a partir dos movimentos missionários, recriando as próprias formas de percepção do mundo, mas mantendo, contudo a auto-percepção de superioridade protestante e estadunidense.

\footnotetext{
${ }^{38}$ Podemos citar, por exemplo, TUCKER, H. C. The Bible in Brazil. Colporter Experiences. Young People's Missionary Movement of United States and Canada. New York: Flemming H. Revell Company, 1902; SMITH, James Porter. An open door in Brazil. Richmond: Prebyterian Committee of Publication, 1925. Há ainda livros sobre a América Latina, mas que, em geral, apresentam capítulos sobre o Brasil, como HALE, Albert. The South Americans. New York:Young People's Missionary Movement of United States and Canada, 1907; SPEER, Robert. South American Problems. New York: Student Volunteer Movement for Foreing Missions, 1917; NEELY, Thomas. South America: Its Missionary Problems. New York, 1909. Todas essas obras estão disponibilizadas para download no site: www.archive.org.
} 


\section{REFERÊNCIAS BIBLIOGRÁFICAS:}

ALSTROM, Sydney E. A Religious History of the American People. New Haven: Yale University Press, 1972.

AZEVEDO, Cecília Silva. A santificação pelas obras: a experiência do protestantismo nos EUA. Tempo. Revista do Departamento de História da UFF, v. 6, n.11, p. 111-129, 2001.

O sentido da Missão no Imaginário Político Estadunidense.

Revista de História Regional - UEPG, Brasil, v. 3, n.2, p. 77-90, 1998.

BAKER, A. G. Twenty-five years of thought concerning protestant foreign missions. In: Journal of Religion, vol. 6, nº $4,1926$.

BARBANTI, M. L. "Colégios americanos de confissão protestante na província de São Paulo: sua aceitação pelas elites progressistas da época”. In: Didática, São Paulo, 1981.

BEACH, Harlam P. Protestant Missions in South America. New York, 1900.

BROWN, Hubert W. Latin America: the pagans, the papists, the patriots, the protestants, and the present problem. New York: Young People's Missionary Movement of the United States and Canada, 1909.

CHARTIER, Roger. À beira da falésia: a história entre certezas e inquietude. Porto Alegre: UFRGS, 2002.

DOSSE, F. História e Ciências Sociais. Bauru, SP: Edusc, 2004.

EDWARDS, WENDY J. D. Forging an ideology for American Missions: Josiah Strong and Manifest Destiny. In: SHENK, Wilbert R. North American Foreign Missions, 1810 - 1914: Theology, Theory, and Policy. Michigan / Cambridge, U.K.: Wm. B. Eerdmans Publishing Co, 2004.

ELIAS, Norbert. O processo civilizador, volume I: uma história dos costumes. Rio de Janeiro, Zahar, 2011.

FERREIRA, Valdinei Aparecido. Protestantismo e Modernidade no Brasil da utopia à nostalgia. São Paulo: Ed. Reflexão, 2010.

FONSECA, Carlos da. Deus está do nosso lado: Excepcionalismo e Religião nos EUA. In: Revista Contexto Internacional. Rio de Janeiro, vol. 29, nº 1, janeiro/junho 2007.

GAMMON, S. R. The Evangelical Invasion of Brazil or a half century of Evangelical Missions in the Land of Southern Cross. Richmond, Presbyterian Commitee of Publications, 1910.

GOUDSBLOM, Johan. A Religião Cristã e o Processo Civilizador Europeu. In: Impulso, Piracicaba, 14 (34), 2003, p. $37-39$. 
HOBSBAWN, Eric. A Era dos Impérios, 1875 -1914. São Paulo: Paz e Terra, 2011.

HUTCHISON, Willian R. The Americanness of the Social Gospel; An Inquiry in Comparative History. In: Church History, 1974, $\mathrm{n}^{\circ}$ 44, pp 367-368. Disponível em http://www.jstor.org/discover/10.2307/3164037?uid=3737664\&uid=2129\&uid=2\&uid=70\&u $\underline{\mathrm{id}=4 \& \operatorname{sid}=21101255891167}$.

JUNQUEIRA, Mary A.. Representações políticas do território latino-americano na Revista Seleções. Rev. bras. Hist., São Paulo, v. 21, n. 42, 2001.

KLING, David W. The New Divinity and the Origins of the American Board of Commissioners for Foreign Missions. In: SHENK, Wilbert R (editor). North American Foreign Missions, 1810 - 1914: Theology, Theory, and Policy. Michigan / Cambridge, U.K.: Wm. B. Eerdmans Publishing Co, 2004.

LOPES, E. P. e LOPES, N. C. S. Igreja e escola de mãos dadas: a educação como práxis teológica na consolidação do presbiterianismo no Brasil. In Revista Caminhando v. 14, n. 2, p. 29-42.

MATA, Sérgio da. História e Religião. Belo Horizonte: Autêntica Editora, 2010.

MATOS, Alderi Souza. O Colégio Protestante de São Paulo: um estudo de caso sobre o lugar da educação na estratégia missionária da igreja. In: Fides Reformata, 4/2, 1999.

MENDONÇA, A. G. O Celeste Porvir. A inserção do protestantismo no Brasil. São Paulo: Editora da Universidade de São Paulo, 2008.

McGRATH, Alister E. e MARKS, and Darren C. The Blackwell Companion to Protestantism. Blackwell Publishing, 2003.

OLIVEIRA, Guilherme F. 'O Brasil é nossa Samaria': providencialismo e representações de Brasil em The Evangelical Invasion (1910), de Samuel R. Gammon. In: I Encontro de Pesquisa em História da UFMG, 2012, Belo Horizonte. Anais Eletrônicos do I Encontro de Pesquisa em História da UFMG, 2012. v. 3. p. 55-67.

- "Para a glória de Deus e para o progresso dos homens": pensamento missionário norte-americano e representações de Brasil a partir The Evangelical Invasion (1910), de Samuel R. Gammon. Dissertação apresentada ao Programa de Pós-Graduação em História da Universidade Federal de São João del-Rei, 2014.

PEREIRA, Rodrigo da Nóbrega Moura. A salvação do Brasil: as missões protestantes e o debate político-religioso do século XIX. Tese (doutorado). Universidade do Estado do Rio deJaneiro: IFCH, p. 73 - 76, 2008.

PRATT, M. L. Os olhos do império: relatos de viagem e transculturação. Bauru: SP, 1999.

Oficina do Historiador, Porto Alegre, EDIPUCRS, v. 7, n. 2, jul./dez. 2014, p. 97-117. 
PORTER, Andrew. Missions and Empire, c. 1873 -1914. Cambrigde Histories Online: Cambridge University Press, 2008, o. 560 - 575.

REILY, Duncan Alexander. História Documental do Protestantismo no Brasil. $3^{\mathrm{a}}$ Ed. São Paulo: ASTE, 2003.

SANTOS, Lyndon de Araújo. Protestantismo e modernidade: os usos e sentidos da experiência histórica no Brasil e na América Latina. Projeto História, São Paulo, n.37, p. 180, dez. 2008.

SHENK, Wilbert R (editor). North American Foreign Missions, 1810 - 1914: Theology, Theory, and Policy. Michigan / Cambridge, U.K.: Wm. B. Eerdmans Publishing Co, 2004.

SILVA, Eliane Moura. "Os Anjos do Progresso no Brasil": as missionárias protestantes americanas (1870 - 1920). In: Rever, ano 12, nº 1, jan./jun. 2012.

Entre religião, cultura e história: a escola italiana das religiões. In:

Revisa de Ciências Humanas, Viçosa, v. 11, n. 2, p. 232, jul.dez. 2011.

STANLEY, Brian. Christian missions, antislavery and the claims of humanity, c. 1813 1873. In: Cambridge University Press, 2006. Cambridge Histories Online. Cambridge University Press.

Missions, Empire and the Hierarchy of Civilization. In: The World Missionary Conference, Edinburgh 1910. Cambridge: Eerdmans, 2009.

SIRINELLI, Jean-François. Os Intelectuais. In: RÈMOND, R. REMOND, René (orgs). Por uma história política. Rio de Janeiro: Editora FGV, 2003.

TILLICH, Paul. Perspectivas da Teologia Protestante nos séculos XIX e XX. São Paulo: Aste, 2010.

TUCKER, H. C. The Bible in Brazil. Colporter Experiences. Young People's Missionary Movement of United States and Canada. New York: Flemming H. Revell Company, 1902.

USTORF, W. Protestantism and Missions. In: McGRATH, Alister E. e MARKS, and Darren C. The Blackwell Companion to Protestantism. Blackwell Publishing, 2003.

VIEIRA, David Gueiros. O protestantismo, a maçonaria e questão religiosa no Brasil. Distrito Federal: Editora UNB, 1980.

WATANABE, T. H. B. De Pastores a Feiticeiros: a historiografia do protestantismo brasileiro (1950-1990), Dissertação de Mestrado, UMESP, 2006.

WILLAIME Jean-Paul. $O$ protestantismo como objeto sociológico. In: Estudos da Religião: Revista Semestral de Estudos e Pesquisas em Religião. São Bernardo do Campo: Universidade Metodista de São Paulo, ano XIV, no 18, p. 13 - 37, jun. 2000. 
ARTIGO ENVIADO EM: 12/02/2014

ACEITO PARA PUBLICAÇÃO EM: 24/05/2014

Oficina do Historiador, Porto Alegre, EDIPUCRS, v. 7, n. 2, jul./dez. 2014, p. 97-117. 